\title{
Fontes orais e história do Rio Grande do Sul: \\ Novas perspectivas ou falsos avanços?
}

\author{
Rejanne Silva Penna*
}

\section{Introdução}

A FORMULAÇÃo DE UM "PROBLEMA HISTÓRICO" é fundamental ao trabalho do historiador, constituindo o verdadeiro centro da investigação. É isso o que proponho: pensar como o debate sobre as fontes orais se constrói como problema metodológico. O tema que abordo, uma reflexão sobre metodologia, encontra-se inserido em determinada realidade, buscando a própria historicidade da História Oral. Para tanto, enfoco a utilização das fontes orais em trabalhos relacionados à História do Rio Grande do Sul ${ }^{1}$.

Selecionei três dissertações de mestrado em História, realizadas entre as décadas de 1980 e 1990, que utilizaram fontes orais. Considero que a produção acadêmica é representativa do estágio em que está a reflexão histórica, porque se espera que a Academia exija um nível de coerência e rigor metodológico que teste, discuta, aprove e, posteriormente, generalize suas experiências de pesquisa. É consenso que, se muitas

* Centro Universitário La Salle.

1 Este texto é resultado de parte do processo de pesquisa que desenvolvo em minha tese de Doutoramento, na PUC (RS), sob a orientação da Prof.Dra.Núncia Constantino. 
inovações em termos de historiografia não partiram da Academia, foi lá que boa parte delas tiveram início e desenvolvimento.

\section{A renovação historiográfica brasileira: brechas para a História Oral}

Após um longo período de marasmo, os anos setenta assistiram, se não a uma revolução epistemológica, a algumas transformações significativas na interpretação e escrita da História. Buscava-se superar um tempo em que se trabalhava sempre as mesmas técnicas de investigação, acompanhadas das fontes e temas tradicionais (ver Lapa, p. 70, 1976) e, dominando a tudo, o autodidatismo dos integrantes do Instituto Histórico e Geográfico Brasileiro e dos diferentes Institutos Históricos dos Estados. Posteriormente, os próprios Institutos Históricos e Geográficos sofreram processos de modernização, com o ingresso gradual de profissionais com formação acadêmica em História.

O contexto político-social brasileiro do período contribuiu para que visões alternativas ou chamadas "de esquerda" abrissem espaço para a introdução de novas práticas de pesquisa, buscando lugar nas Universidades que, em sua maioria, ainda concentravam seus estudos no Brasil colonial e no século XIX, chegando, no máximo, a abordar o período republicano, até a Revolução de 1930. O impulso final ocorreria ainda na década de 1970, com a implantação da pós-graduação em História no Brasil. Mais adiante, os anos oitenta representaram a consolidação dos programas de pós-graduação em História e Ciências Sociais, enfocando a História Social e Cultural. Vários pesquisadores encontraram espaço para produzir suas pesquisas, explorando temáticas como a classe trabalhadora brasileira, a história de bairros, as minorias e grupos discriminados, como negros e mulheres.

Persistem dúvidas quanto a uma renovação de caráter profundo, mas todos concordam que em termos de utilização de fontes e ampliação de temas, o campo para o historiador alargou-se consideravelmente. Do processo de ampliação das fontes e da dominância, nestes cursos, da pesquisa em história do Brasil, com a possibilidade de enfocar a contemporaneidade, surgiu, e gradativamente ampliou-se, o espaço para a História Oral. 


\section{Fontes orais e história do Rio Grande do Sul: um estudo de caso}

Acrescento mais um elemento na reflexão: a historiografia local ${ }^{2}$, mais especificamente a do Rio Grande do Sul. Nos últimos anos, especialmente a partir da década de 1970, tem crescido muito o número de pesquisas e estudos de historia local, onde se insere a história do Rio Grande do Sul O fato tem várias explicações, passando tanto pelo esgotamento das grandes sínteses até então predominantes, como pela instalação e desenvolvimento de cursos de graduação e pós-graduação em todo o interior e capitais do país, permitindo, pela primeira vez em algumas regiões, a formação de uma geração de pesquisadores dotada de embasamento científico e comprometida com temas locais. Paralelamente, ocorre uma revalorização da história, com comunidades pressionando para que suas trajetórias sejam estudadas e publicadas.

Mas será que esta renovação é significativa na escrita da história do Rio Grande do Sul? De acordo com suas propostas modernizadoras, os historiadores estão ousando na utilização das fontes, diferenciando-se dos métodos tradicionais de análise e estruturação dos trabalhos? A base dos novos trabalhos ultrapassa as fontes oficiais, explorando as fontes orais para além de cotidianos e curiosidades? Em que medida os estudos sobre memória e fontes orais foram incorporados nas investigações sobre história do Rio Grande do Sul?

Qualquer pesquisador que utilize fontes orais e esteja medianamente informado sobre sua utilização, percebe haver um grande número de pessoas trabalhando em História Oral por conta própria, a fim de documentar as histórias de grupos específicos, definidos por ocupação ou relação, como artistas, unidades do Exército, médicos; ou atividades e eventos específicos, como greves, etc. Muitas vezes, a reflexão teórico-metodológica, quando há, passa ao largo dos avanços em nossa área.

2 Neste artigo utilizarei o conceito de local relacionado a trabalhos direcionados a algum aspecto da história do Rio Grande do Sul. Não discutirei os conceitos de local, regional ou micro-história, remetendo-os aos trabalhos de Henrique Spada (1999) e Janaína Amado (in Silva, 1990). 
Os historiadores com formação acadêmica freqüentemente criticam as pesquisas que utilizam a História Oral para "dar voz aos oprimidos" ou os que procuram, por uma espécie de "amor à cidade", resgatar a História de seu município. Analisam estes trabalhos como sendo de caráter meramente empírico ou predominantemente político. Mas será que os próprios trabalhos acadêmicos que utilizam as fontes orais inovam metodologicamente?

Podemos buscar as respostas especialmente na produção dos Cursos de Pós-Graduação, pois, conforme observou Marchi: “(...) embora, na sua maioria, atendam à necessidade de titulação para se construir uma carreira acadêmica, elas representam um processo de amadurecimento intelectual e permitem definir o perfil do pesquisador. Além disso, são produções que foram submetidas a processos públicos de avaliação através de bancas examinadoras qualificadas e se enquadram dentro dos padrões mínimos de qualidade aceitos pela comunidade científica. Acrescente-se ainda que, na sua maioria, trazem contribuições significativas na área de domínio de temas específicos, fazem uso adequado de metodologias de pesquisa e trabalham com fontes que forneciam credibilidade e consistência aos dados e às análises produzidas" (Marchi et al., p. 135).

Não é meu objetivo analisar a integridade dos trabalhos, mas apenas o que se relaciona à incorporação das fontes orais nos mesmos, no momento em que realizaram as defesas de suas dissertações. Obviamente que os métodos e concepções teóricas dos autores sobre fontes orais evoluíram desde então. Alguns já concluíram seus doutorados e, na época, exercitavam os primeiros vôos como pesquisadores.

Mas, ratifico, o objetivo aqui não é analisar a obra dos autores em si, mas apenas a utilização das fontes orais, nos momentos específicos das defesas das dissertações, considerando-os representativos do estágio em que estavam no momento em que foram feitas as pesquisas envolvendo fontes orais.

\section{Construindo o instrumento de análise}

A forma de operacionalização da análise a ser realizada necessariamente deve ter elasticidade para não engessar o processo de pesquisa. 
Ou seja, não busco com a coleta de dados comprovar hipóteses consolidadas, mas a partir de um foco inicial, de sentido apenas orientativo, desenvolvo categorias, conceitos e conclusões.

Ao trabalhar com livros, dissertações e teses estou lidando com conteúdos, logo, senti a necessidade de conhecer e escolher metodologias de análises que auxiliassem minha investigação para além do mero empirismo. A proposta exclui a lingüística do texto, que se restringe à análise de um texto em si, estudando as relações de coerência e coesão, responsáveis pela tessitura. Além de não possuir formação para dar conta de tal tarefa, esta não integra meus objetivos.

O que é pertinente em minha pesquisa, que visa a investigar a utilização das fontes orais na historiografia do Rio Grande do Sul, é relacionar os diferentes trabalhos, suas formações discursivas ${ }^{3}$, a incorporação das fontes orais e os resultados advindos de tal conjugação.

Para possibilitar a análise dos conteúdos integrantes dos textos de história do Rio Grande do Sul em que são utilizadas as fontes orais, no recorte temporal proposto, utilizei categorias em que os elementos identificadores das diretrizes dos trabalhos pudessem ser contidos. $\mathrm{Na}$ construção dessas categorias, considerei fundamental que servissem para entender os significados de um texto, levando o contexto em consideração, além do conteúdo explícito, o autor, o destinatário, as formas de codificação e transmissão da mensagem e, principalmente, o tratamento da fonte oral. Trabalhando com estes elementos, direcionei a análise pressupondo que o produtor da mensagem seleciona seu conteúdo, seja por considerar este ou outro elemento mais importante, fazendo parte ou não do seu sistema de crenças e referências.

Minha classificação baseia-se numa definição original de Laswell, em que este caracteriza a comunicação a partir de seis questões: Quem fala? Para dizer o que? A quem? De que modo? Com que finalidade? Com que resultado? Utilizando esta definição, podemos categorizar os objetivos da análise de conteúdo de acordo com a orientação que este toma

3 Utilizarei o conceito de Pêcheux em que "a formação discursiva é aquilo que numa formação ideológica dada, isto é, a partir de uma posição numa conjuntura específica, determinada pelo estado de luta de classes, delimita o que pode e deve ser dito". (1988, p. 160) 
em relação a estas seis questões. A partir das categorias-base, desenvolvo-as levando em consideração a especificidade da pesquisa, subdividindo a análise de cada trabalho escolhido em duas etapas: a) informações gerais sobre o trabalho e b) tratamento das fontes orais.

Após o mapeamento por item das informações gerais, cruzarei os resultados com aqueles referentes ao tratamento das fontes orais. Observo que, por vezes, um trabalho terá seus elementos inseridos em mais de uma categoria, como, por exemplo, no tratamento das fontes orais. Em alguns capítulos o autor poderá subordiná-las às fontes escritas; em outros, elas assumirão papel preponderante. O resultado deverá revelar de que forma determinado tipo de orientação historiográfica utilizou as fontes orais. Ao final, comparando os itens, estará facilitada a análise do panorama da utilização das fontes orais em trabalhos acadêmicos envolvendo História do Rio Grande do Sul.

\section{1 Justificativa das decisões tomadas}

na construção de categorias iniciais

Mesmo partindo de uma série inicial classificatória, as categorias não tomaram a forma definitiva a priori, pois pretendi que elas emergissem da própria leitura dos trabalhos, valorizando as convergências, mas criando novas categorias para incluir as divergências.

A seguir, passo a explicar as categorias construídas:

\section{Informações gerais sobre o trabalho}

Item: a unidade de análise denomina-se item, de acordo com meu campo de investigação. Minha decisão relaciona-se à divisão feita por Maria Laura Franco (1996, p. 19), em que esquematiza os tipos de unidade de análise possíveis, sua caracterização, campos de aplicação e limitações. No caso, delimito o item utilizando apenas trabalhos acadêmicos de história do Rio Grande do Sul, no recorte temporal proposto, com a utilização de fontes orais, exclusivamente ou não.

Título do trabalho: informação complementar ao item.

Ano: o ano permite situar o período de publicação, levando em consideração a importância do contexto, para situar as condições de produção do trabalho.

Instituição: permite verificar de onde fala o autor. 
Objetivos do trabalho: para que foi escrito, determinando o alcance da obra e o desenvolvimento da proposta.

Categoria: determina a forma e direciona as exigências de aprofundamento do tema ou sub-temas do trabalho

Conteúdo da formação discursiva dominante: de acordo com Maria Laura Franco: “o investigador, ao ler ou ouvir determinada posição sobre o papel do psicólogo, para produzir inferências acerca do que leu ou ouviu, deve compatibilizar o conteúdo da 'fala' com alguma corrente teórica explicativa” (1986, p. 16). O conteúdo emergente do discurso será comparado ou a algum tipo de teoria ou linha de desenvolvimento de raciocínio, compondo um painel de concepções que se relacionam de uma forma ou outra com as fontes orais.

A quem? Focaliza o receptor. Explica o público-alvo do trabalho, influenciando na forma e nos destaques aos temas e às fontes.

\section{Tratamento das fontes orais}

As categorias foram construídas visando integrar a utilização das fontes orais no esquema geral do trabalho. Não especificarei a construção de cada uma delas, à medida que, detalhadas, se auto-explicam.

Nesse sentido, busco compreender a utilização das fontes orais, analisando formas diferenciadas no tratamento das mesmas que, combinadas e reunidas às informações gerais sobre os trabalhos, esclarecerão sobre a forma final de inserção das fontes orais nas pesquisas, seus avanços e limites.

\section{Análise dos trabalhos}

\subsection{Informações gerais sobre os trabalhos}

\section{Item 1}

Titulo do trabalho: A formação do trabalhador fabril: história oral em Ijuí/RS.

\section{Ano: 1989}

Instituição: Departamento de História / Instituto de Filosofia e Ciências Humanas / Programa de Pós-Graduação da Unicamp Autor: Regina Weber 
Objetivos do trabalho: Estudo de caso acerca dos trabalhadores ijuienses "para melhor conhecer essa classe social em sua dimensão nacional e histórica, enxergando-a por outro ângulo que não o da 'fala dos outros"” (p. 6).

Categoria: Dissertação de mestrado. Orientação: Michael McDonald Hall.

Conteúdo e formação discursiva dominante: Considera "a influência de uma certa vertente da historiografia inglesa, presente, por exemplo, na obra de Edward P. Thompson, com a qual me familiarizei antes de elaborar o projeto de tese" (p. 5).

Menciona como concepções integrantes do trabalho referências a Edgar de Decca (Introdução do $2^{\circ}$ vol. de $A$ Classe Operária no Brasil) (p. 5).

"Em qualquer unidade produtiva o processo de trabalho é um lugar, um momento em que o capital exerce sua dominação sobre o trabalho. Porém, em fábricas pequenas, onde as relações de trabalho são construídas com laços pessoais entre empregados e patrões, mesmo porque estes estão ali, cotidianamente presentes e acessíveis, a percepção das contradições geradas por esta dominação é bem mais obstaculizada que nas grandes indústrias modernas".

A quem: Público acadêmico.

\section{Item 2}

Titulo do trabalho: Guardar e celebrar o passado: O Museu de Porto Alegre e as memórias da cidade.

Ano: 1998

Instituição: Instituto de Filosofia e Ciências Humanas / Programa de Pós-Graduação em História da Universidade Federal do Rio Grande do Sul

Autor: Zita Possamai

Objetivos do trabalho: A pesquisa abrange basicamente as décadas de 1970 e 1980 e busca analisar as representações e práticas envolvidas na história do museu.

Categoria: Dissertação de mestrado. Orientação: José Augusto Avancini.

Conteúdo e formação discursiva dominante: "O pressuposto principal da investigação é de que o percurso que leva um objeto ou conjunto de 
objetos a fazerem parte do acervo de um museu não é, de modo algum, aleatório, dele fazendo parte vontades, desejos e interesses de indivíduos, grupos ou instituições da sociedade" (p. 7).

"Assim, não se pode pensar no museu como um lugar neutro, mas como um espaço de relações objetivas que se estabelecem entre seus agentes e entre estes e outros agentes da sociedade” (p. 138).

"Dessa forma, o museu pode ser caracterizado como um 'espaço de luta material e simbólica’ em torno da construção e veiculação de memórias, sejam estas individuais ou coletivas" (p. 138).

A quem: Público acadêmico.

Item 3

Titulo do trabalho: Os filhos da escravidão: memórias de descendentes de escravos da região meridional do Rio Grande do Sul.

Ano: 1992

Instituição: Instituto de Filosofia e Ciências Humanas / Curso de Pós-Graduação em História da Pontifícia Universidade Católica do Rio Grande do Sul

Autor: Agostinho Mario Dalla Vecchia

Objetivos do trabalho: Estudo histórico da escravidão na região meridional do Rio Grande do Sul, envolvendo a área de dezoito municípios do extremo-sul do território brasileiro. O trabalho é uma investigação da história e da memória dos descendentes de escravos da mesma região.

Categoria: Dissertação de mestrado. Orientação: Mario Maestri Filho.

Conteúdo e formação discursiva dominante: "O trabalho é desenvolvido em quatro capítulos considerando a história como um processo vivo de relações econômicas, políticas, educativas, familiares, recreativas e religiosas" (p. IV).

"Partimos da idéia que a história é feita das relações vivas do homem com a natureza, com os outros e com a divindade. Do jeito como o homem se relaciona com a natureza por mediação do trabalho, concretiza determinados modos de relação econômica com os demais. Quando se trata de decisões entre os grupos da sociedade, o modo como se conduz a vida social determina as relações políticas no seu sentido mais amplo. O processo de transmissão da cultura de um povo às novas gerações estabelece as relações educativas" (p. 3). 
"Na visão dialética marxista, acredita-se que o trabalho e a resistência são os elementos articuladores da vida e da história” (p. 136).

A quem: Público acadêmico

Os exemplos escolhidos envolvem três grandes universidades e perpassam quase dez anos (1989 a 1998). Todos fazem parte de experiências iniciais de pesquisa (dissertações de mestrado) e investigam processos em que estão envolvidas categorias sociais não dominantes (trabalhadores, doadores de objetos e escravos). Ou seja, mesmo que no caso do trabalho de Zita Possamai não necessariamente esteja envolvida alguma categoria subalterna da sociedade, não se pode dizer que tenha o poder de uma voz oficial para deixar seu registro. Logo, a proposta de utilizar fontes orais em seus trabalhos é ousada e coerente com os objetivos de suas pesquisas.

Na categoria "orientação teórica”, Weber busca unir os pressupostos da Escola Social Inglesa com peculiaridades locais, como os laços pessoais que se criam entre patrões e empregados, para melhor compreender situações e opiniões, estabelecendo uma malha mais fina que a fornecida pelas linhas gerais dos pressupostos dessa linha teórica. Possamai trabalha com a noção de memória socialmente construída e, portanto, objeto de disputas que poderão ser identificadas no estabelecimento dos lugares da memória e das relações entre objeto e representação. Em Dalla Vecchia, as idéias expostas são ligadas à determinada interpretação marxista, destacando os processos de trabalho como palco privilegiado para analisar a resistência dos oprimidos. Não cede a economicismos redutores e procura trabalhar com a dimensão cultural dialeticamente unida aos componentes econômicos e políticos.

Em comum aos três autores, a concepção de que a sociedade desenvolve-se por intermédio de lutas, dominações, resistências e acomodações, enfatizando a importância de integrar as peculiaridades locais aos grandes processos estruturais. É perfeitamente coerente a escolha da utilização das fontes orais, como busca de vozes alternativas, aos discursos dominantes nas concepções e objetivos dos três trabalhos.

\section{$5.2 \bigcirc$ tratamento das fontes orais}

Os dados selecionados e inseridos nas categorias correspondentes permitem chegar a muitas conclusões. Não pretendendo esgotá-las: 
é complexo afirmar que os três autores subordinaram a utilização das fontes orais a um tema pré-determinado. Ocorre que não explicitam por que meios o escolheram nas introduções de seus trabalhos, apenas destacando sua relevância e contribuição para a compreensão de determinados processos. Seria até possível que, por intermédio de conversas e sondagens com pessoas que vivenciaram experiências, tenham determinado seu tema. Entretanto, pelos dados disponíveis, pode-se concluir que os autores já tinham um tema pré-escolhido e que as fontes orais auxiliaram no desenvolvimento da pesquisa, não o determinando, mas nos três casos, indicando muitos caminhos essenciais.

Ao longo dos trabalhos, os autores nem sempre trataram as fontes orais de forma homogênea, o que determinou, por vezes, classificações em mais de uma categoria. Em Dalla Vecchia, por exemplo, observa-se que os temas formam-se ora por leitura sobre a escravidão, ora emergem das entrevistas. Em alguns casos, como no item religiosidade, o raciocínio foi estruturado basicamente em fontes escritas. As fontes orais, no caso específico, adquiriram caráter secundário e prestaram-se apenas para detectar a diversidade religiosa dos negros. Os conflitos de 1893, 1923, 1930 e outros não são arrolados apenas porque surgem nas entrevistas, mas sim pela influência de eventos valorizados pela historiografia. Entretanto o autor privilegia estes temas tradicionais com a visão da fonte oral, no que inova.

Verifica-se que as fontes orais têm, nos três trabalhos, um papel essencial à investigação, não ocupando, na relação com a fonte escrita, lugar subordinado. Por vezes as informações orais são comparadas ou referendadas pelas fontes escritas, entretanto, jamais são desautorizadas por estas ou colocadas em dúvida por divergirem.

Há uma valorização da fonte oral, também no sentido de produzir condições para as reflexões e problematizações mais importantes dos trabalhos. Entretanto, os três autores também justificam a utilização das fontes orais, em determinados caminhos de seus trabalhos, não por uma opção metodológica, mas em razão de carência de fontes escritas.

Em um dos trabalhos (Dalla Vecchia), a opção pela fonte oral tem por vezes o caráter de contestação a versões consagradas e vistas pelo autor como conservadoras, o que muitas vezes é a razão da escolha das fontes orais pelos historiadores. Dois dos autores (Possamai e Dalla 
Vecchia) ressaltam a fonte oral como possibilidade de reconstruir determinados sistemas de representações não contemplados pelas fontes oficiais (Possamai), bem como trazer à tona outra versão da história (Dalla Vecchia).

Também se observa uma relação de complementaridade entre as fontes orais e escritas nos trabalhos. Nesse caso, há carência de uma reflexão sobre as especificidades de cada tipo de fonte, e, por vezes as fontes orais são tratadas apenas como informação, compondo determinado painel, unidas às fontes escritas. Em alguns casos (trabalhos de Weber e Possamai) não ocorrem maiores problemas por esta prática, à medida que as autoras apenas utilizam o recurso da complementaridade das fontes para casos em que é necessário cotejar informações como número de funcionários, datas, etc, unindo após com representações sobre o período.

Os autores não definem exatamente em que casos utilizarão as fontes orais como painéis de representação. Nesse sentido, apesar das explicações de como consideram as fontes orais e o envolvimento com a questão da memória (Possamai e Dalla Vecchia. Weber esclarece não discutir a questão neste trabalho), incorporam as fontes orais ora como testemunhos de verdade, ora como representações. Não se percebe uma clareza quanto a este aspecto.

Quanto à identificação dos depoentes, os três autores utilizaram métodos diferenciados, desde a impossibilidade de identificá-los (Weber) até a exposição total (Dalla Vecchia). Todos os autores preocupam-se em situar o leitor no contexto passado do depoente, procurando situar suas condições na época pesquisada. Porém, apenas Dalla Vecchia informa sobre a situação do depoente no presente, elemento essencial, considerando-se o caráter dinâmico da memória. Também se preocupou em trazer o maior número possível de elementos identificadores da fonte oral, como fotografia no momento da entrevista, contexto desta, ambiente e atitude do entrevistado.

Quanto à durabilidade e período das entrevistas, os dados foram variados, tendo em comum o expressivo número de pessoas contatadas e duração mínima de uma hora. Os autores optaram por entrevistar individualmente e apenas uma vez cada depoente, o que remete a utilização da fonte oral como testemunho histórico de forma simplificada, sem recorrer à entrevista de caráter aprofundado, quando se trabalha 
determinado tema várias vezes com o mesmo depoente, analisando as variações.

Ao leitor torna-se por vezes impossível verificar até onde as lembranças são induzidas pelo entrevistador e os critérios de escolha deste para a edição dos depoimentos, à medida que apenas um autor (Dalla Vecchia) disponibiliza um anexo com as entrevistas na íntegra. Diga-se de passagem, que também é o único trabalho que transforma as fontes orais em fontes históricas, pois acessíveis no anexo. Dessa forma, mesmo que seguindo o exemplo dos outros dois autores, que omitem as questões no texto do trabalho, pode-se analisar a postura do entrevistador pela transcrição na íntegra, disponível no anexo.

Para incorporar a entrevista no trabalho, todos optaram pela edição do depoimento, a partir dos temas. Mantiveram, entretanto, a linguagem original dos depoentes.

Apenas um autor optou pela entrevista totalmente dirigida (Possamai). Os demais formataram-na como entrevista semidirigida, justificando a investigação sobre um tema específico, mas deixando espaço para o surgimento de novas questões. A opção da entrevista semidirigida talvez seja a que melhor utiliza o potencial para o trabalho com fonte oral. A entrevista dirigida não impede novos caminhos na pesquisa, mas reduz essas possibilidades.

E chegamos a um dos pontos nevrálgicos dos trabalhos: a interpretação dos depoimentos. Os autores não utilizaram nenhuma técnica sistematizada para a análise das entrevistas. É verdade que nenhum deles se omitiu de trabalhar com os conteúdos, entretanto, utilizaram de forma por vezes confusa, conhecimentos históricos ou de outras ciências humanas ou de noções sobre memória, para analisá-los. O resultado é que muitas vezes a riqueza de um depoimento é sub-aproveitada e os avanços já ocorridos por pesquisadores em análise de conteúdo ou de discurso não são incorporados. Fica-se em um nível excessivamente impressionista e irregular.

Verifica-se, a partir da análise dos dados, que, mesmo com carências quanto à interpretação dos conteúdos, o que já deve ter sido superado (em suas referências bibliográficas todos buscavam estudos e referências ao tratamento com fontes orais) e a não disponibilização das entrevistas na íntegra (produção de fontes históricas), os autores não apenas reconhecem a importância da fonte oral em seu trabalho, mas, 
efetivamente utilizam-na como fonte essencial ao desenvolvimento de seu raciocínio histórico.

Uma das críticas mais recorrentes feitas aos historiadores que integram as fontes orais é que as mesmas influenciaram a que o trabalho permanecesse em uma pequena escala, isolada de uma estrutura maior, o que, no caso, além de tornar a pesquisa inútil a um contingente maior de pessoas, possuiria um grave defeito metodológico. Entretanto, todos os três autores buscam trabalhar a peculiaridade local e a abrangência restrita da visão dos depoentes ligando-a a contextos maiores, possibilitando a ligação a processos amplos.

\section{Uma tarefa em construção: \\ a interpretação dos depoimentos}

É de extrema importância a contribuição constatada da fonte oral nos trabalhos analisados. Com Regina Weber, permitiu a reconstrução e compreensão de um quadro mais realista sobre a industrialização em uma pequena cidade, levando em consideração tanto os processos globais como peculiaridades locais, muitas vezes apenas acessíveis por intermédio das fontes orais.

A inclusão das fontes orais no trabalho de Zita Possamai proporcionou informações fundamentais na compreensão da montagem do acervo do Museu. Algumas conclusões importantes que realizou não poderiam ser efetivadas sem o recurso deste tipo de fonte, como, por exemplo, a constatação da pouca preocupação dos doadores em buscar uma relação dos seus objetos com o objeto de estudo do museu.

Agostinho Dalla Vecchia apresenta com as fontes orais, em sua dimensão da pequena escala, quadros vivos e pungentes. Trabalha com uma memória importante para alimentar a problemática frente às afirmações da brandura da escravidão no Rio Grande do Sul. O que pode retirar a força de um depoimento em que a filha, referindo-se ao pai que fora escravo, lembra das marcas que a tortura deixou no seu corpo: "Tinha buracos na cabeça, do porrete que ele levava. Esta eu vi!" (Anexo, p. 62). Em um primeiro olhar, os depoimentos versam sobre banalidades do dia-a-dia que, entretanto, reunidos, formam, aos poucos, um quadro ímpar da escravidão no Rio Grande do Sul. Os relatos 
da vida dos negros imediatamente pós-abolição são fundamentais. Não se encontra esta informação facilmente nas fontes escritas. Os descendentes de escravos são memorizadores privilegiados daquela realidade.

Este é dos raros trabalhos, se não o único, que integra a participação e a visão dos negros em conflitos históricos como de 1893, 1923 e 1930, e contribui a novas problematizações, como por exemplo, a investigação do racismo nas congregações ou ordens religiosas: "Era significativo que naquela época as irmãs de cor não podiam lecionar. Trabalhavam na cozinha" (p. 213).

É difícil não se entusiasmar com esta pequena mostra da utilização das fontes orais em trabalhos acadêmicos, em que os historiadores, na época ainda pesquisadores iniciantes, ousaram enfrentar as polêmicas e as dificuldades que envolvem este tipo de fonte. $O$ resultado foi compensador, pois diferenciou seus trabalhos, apontou novos caminhos e traçou problemáticas fundamentais ao avanço da História como ferramenta essencial à análise dos intrincados caminhos dos homens em sociedade no tempo.

Para avançarmos para além da trajetória desses pesquisadores devemos levantar as questões que devem ser mais bem trabalhadas. Em primeiro lugar, dificilmente outro tipo de fonte histórica tenha sido fruto de tantas discussões, defesas e objeções como a fonte oral. Até hoje, a utilização das fontes orais em pesquisas e publicações de caráter histórico tem sido acompanhada de polêmicas e hesitações.

Parte do problema deve-se ao fato de que a inclusão deste tipo de fonte na historiografia, freqüentemente revestiu-se de caráter empírico, não sendo reconhecido um texto-fundador que norteasse e esboçasse um corpo de proposições unificadas. Mesmo trabalhos envolvendo nomes conceituados como Paul Thompson e Gwyn Prims, entre outros, foram alvo de críticas por parte dos céticos na utilização das fontes orais,questionando, em tese, a credibilidade dessa fonte.

Tais dúvidas não perpassaram a utilização das fontes escritas. Discutiu-se e discute-se, ainda, a interpretação das mesmas, mas seu uso é aceito, indiscutivelmente, por todos os historiadores. Alguns até afirmam ser impossível escrever História sem fontes escritas. As fontes escritas, ao longo do tempo, tiveram seu processo de utilização discutido e aperfeiçoado, resultando em um eficiente aparato de erudição. Mas será que se realizou alguma mesa-redonda para analisar o estado 
psicológico de quem escreveu? Talvez, mas não é a regra. Sabe-se que os interesses e os contextos hoje são levados em consideração na incorporação de todo o tipo de fonte. Mas investigou-se a influência da hora, do ambiente da sala, arquivo, palácio, ou seja lá o que for, da presença de outras pessoas (secretária, criados, polícia - ou quem sabe um filho que veio visitar)? Será que a posição e a cadeira influíram na escrita? Pode parecer ironia ou exagero, mas com as fontes orais chega-se a fazer isso!

Existem vantagens e riscos nessa exposição e esmiuçar constantes. A desorientação frente às polêmicas direcionou certo número de pesquisadores a optar pelo caminho menos arriscado de apenas cotejar depoimentos e inseri-los nos trabalhos e pesquisas como "visões de mundo", "imaginários e representações", sem nenhuma indagação do porquê daquela determinada visão e ponto. Felizmente, não foi o caso dos trabalhos analisados no presente artigo.

Os desafios que enfrentam os historiadores que buscam trabalhar com as fontes orais são de grande amplitude, mas o aprofundamento, que nos faz tangenciar outras áreas do conhecimento, pode paralisarnos e fazer-nos desistir de analisar a fonte oral e o sentido de seu depoimento. Mas não temos saída se quisermos ir adiante, pois se evidenciam as lacunas que deixamos não utilizando os meios ao nosso alcance para analisar esse tipo de fonte e efetivamente contribuir para a constante renovação historiográfica. É claro que a nossa abordagem de um discurso não será a de um lingüista. Esta não é nossa formação e podemos contribuir de outra maneira. Possuímos específicos e valiosos conhecimentos que, entretanto, necessitam ser complementados com a experiência de outras áreas, com estudos a respeito do que podemos aprender e incorporar ao aparelho de erudição da História para nossa trajetória de análise.

Grupos ou pesquisadores individualizados já fazem isso, mas os resultados ainda são pouco conhecidos e divulgados. Carecemos de maior exposição dos exercícios de análise da fonte oral, pois somente dessa forma poderemos incorporar críticas e sugestões para a generalização de nossos saberes recém conquistados. 


\section{Referências bibliográficas}

FRANCO, Maria Laura P. Barbosa. O que é análise de conteúdo. In: Cadernos de Psicologia da Educação. São Paulo, PUC-SP (7), 1-31, ago/86.

LAPA, José Roberto do Amaral. A História em questão: historiografia brasileira contemporânea. Petrópolis, Ed. Vozes, 1976.

MARCHI, Euclides, et. al. In: Revista Brasileira de História. São Paulo, V. 13, set/ 92-ago/93.

REVEL, Jacques (org.). Jogos de escalas: a experiência da microanálise. Rio de Janeiro, Editora Fundação Getúlio Vargas, 1998.

SILVA, Marcos. República em Migalhas. São Paulo, Ed. Marco Zero/CNPQ, 1990.

\section{Teses e dissertações analisadas:}

DALLA VECCHIA, Agostinho Mario. Os filhos da escravidão: Memórias de descendentes de escravos da Região Meridional do Rio Grande do Sul. Dissertação de Mestrado apresentada ao Departamento de História do Instituto de Filosofia e Ciências Humanas da Pontifícia Universidade Católica do Rio Grande do Sul. 1992.

WEBER, Regina. A formação do trabalhador fabril: história oral em ljuí/RS. Dissertação de Mestrado apresentada ao Departamento de História do Instituto de Filosofia e Ciências Humanas da Universidade de Campinas. 1989.

POSSAMAI, Zita. Guardar e celebrar o passado: O Museu de Porto Alegre e as memórias da cidade. Dissertação de Mestrado em História apresentada ao Instituto de Filosofia e Ciências Humanas da Universidade Federal do Rio Grande do Sul. 1998.

Resumo: A partir dos anos 1970 percebe-se uma renovação nos trabalhos envolvendo história regional. Novas temáticas são abordadas, temas tradicionais são enfocados sob perspectivas inovadoras. O processo é acompanhado pela ampliação da noção de fonte histórica. Todos os vestígios são válidos para auxiliar na interpretação histórica. As fontes orais, recusadas por muito tempo pela historiografia tradicional, tomam, pouco a pouco, espaço privilegiado na nova história regional. Hoje, trabalhos envolvendo grupos nas universidades e instituições públicas e privadas utilizam de forma intensa esse tipo de fonte. Será que a 
ampliação do número de pesquisadores que se envolveram com as fontes orais e utilizaram os resultados obtidos em suas pesquisas foi acompanhada, no mesmo nível, pelo aprofundamento metodológico, o que implicaria em avanços reais na discussão historiográfica?

PALAVRAS-ChAVE: historiografia; fontes orais; metodologia; História do Rio Grande do Sul.

Oral Sources and the Historiography of Rio Grande do Sul:

New Perspectives or False Advances?

ABstract: After the 1970's, there has been a marked renovation in researches involving history. New themes have been approached and traditional themes have been focused on under innovative perspectives. The process is accompanied by the amplification of the notion of historical source and all the remains are valid in order to assist historical interpretation. Oral sources, which had been rejected by traditional historiography for a long time, have slowly gained space in the new historiography. Nowadays, researches involving groups in universities and public and private institutions use intensely this type of source. Was the increase in the number of researchers that got involved with oral sources and made use of results obtained in their researches accompanied by a methodological deepening, which would implicate in real advances in the historiographic discussion?

KEYwORDs: historiography; oral sources; methodology; History of Rio Grande do Sul 